\title{
Outcomes of clitoral reconstruction in women that experienced genital mutilation and/or genital cutting: 10 years of experience in the Netherlands
}

\author{
Refaat Bari Karim ${ }^{1}$. Disha Elizabeth Nihar Bari Karim² . Judith Johanna Maria Louise Dekker ${ }^{3}$. \\ Maria Johanna Middelburg ${ }^{4}$
}

Received: 21 October 2021 / Accepted: 25 January 2022 / Published online: 1 March 2022

(c) The Author(s) 2022

\begin{abstract}
Background The empowerment of women that migrated from Africa and the Middle East to the Netherlands increased the awareness and demand for clitoral reconstruction in women that experienced genital mutilation and/or genital cutting (FGM/C). Our aim was to investigate the outcomes of FGM/C-corrective surgeries conducted over a 10-year period.

Methods We recruited 72 patients with FGM/C from January 2010 to January 2021. All patients received counseling and underwent strict selection for surgery. Clitoroplasty was performed according to the Foldès technique. Patients were followed for a mean of 13 months. Surgery outcomes were evaluated with a questionnaire.

Results Of 72 women recruited, 19 (26\%) were unsuitable for clitoral reconstructive surgery, due to comorbidities that required prior treatment $(n=5)$, unrealistic expectations about the surgery outcome $(n=12)$, a desire for information only about the procedure $(n=2)$, a choice to treat only a Bartholin cyst $(n=1)$, or previous surgery for FGM/C $(n=1)$. As of January 2021, 45 patients had undergone surgery and were included in the present study. After surgery, we performed primary clitoroplasty. Postoperatively, we observed four minor complications. Among all 45 patients, 35 (76\%) reported satisfaction with the treatment and improvements in self-respect. Four woman reported disappointment in the aesthetic results, but they were satisfied with the surgery. Six women were lost to follow-up.

Conclusions After well-specified preoperative patient selection, clitoral reconstructive surgery led to a high patient satisfaction rate with minor surgical complications. Among patients that desire reconstruction, this surgery can be performed after careful counseling.
\end{abstract}

Level of evidence: Level IV, Risk/Prognostic study.

Keywords Female genital mutilation $\cdot$ Genital reconstruction $\cdot$ Primary clitoroplasty

\section{Introduction}

Disha Elizabeth Nihar Bari Karim

rbkarim@dokterkarim.nl

1 A Klinieken, Huis ter Heide, the Netherlands

2 Vumc School of Medical Sciences, Vrije Universiteit, Amsterdam, the Netherlands

3 The Department of Department of Gynaecology and Obstetrics, Amsterdam Universitair Medische Centra, Location VUmc, Amsterdam, the Netherlands

4 Founder \& Director, Middelburg Human Rights Law Consultancy, Vinkeveen, the Netherlands
The World Health Organization defines female genital mutilation and/or cutting (FGM/C) as any procedure that injures or removes part or all of the external female genitalia for non-medical reasons [1]. FGM is practiced as a cultural or tribal custom that perpetuates gender inequality. FGM is currently widely practiced in sub-Saharan Africa, the Middle East, and to a lesser extent, Asia. Moreover, it is presently practiced among European immigrants [2]. FGM/C is typically performed domestically, by a tribal practitioner with a knife or razor blade, and without anesthesia. About 200 
Fig. 1 Normal anatomy and types I to III of Female Genital Mutilation (type IV is not included): A Normal anatomy. B: Type I: removal of the external clitoris and clitoral hood. $\mathbf{C}$ Type II: type I plus the complete or partial removal of the minor labia. D Type III: type II plus removal of the minor and major labia, followed by suturing (this figure was produced by the authors)
A
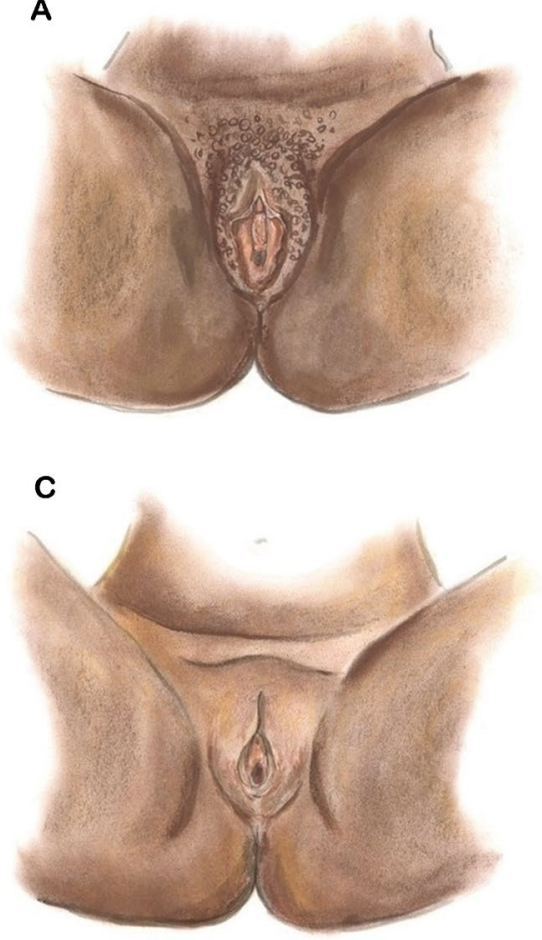

B

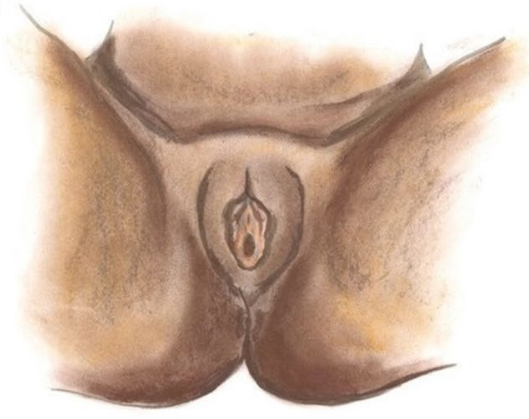

D

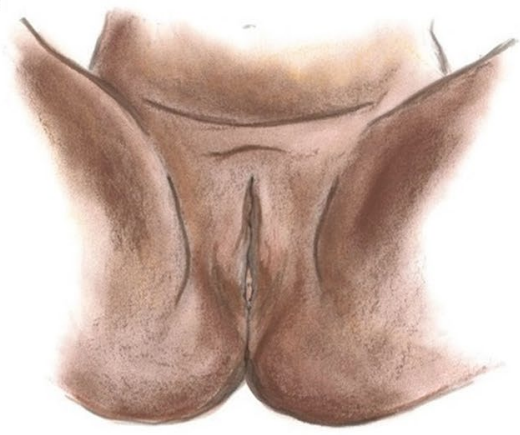

million girls worldwide have experienced FGM/C, at various ages, ranging from young childhood to adolescence [1].

FGM/C entails one or more mutilations that vary with different regions and cultures (Fig. 1). These procedures are categorized as follows: type I: complete or partial removal of the external clitoris and clitoral hood; type II: type I plus the complete or partial removal of the minor labia; type III (infibulation), complete or partial removal of the minor and major labia, followed by suturing the wound closed, except for a small cutaneous orifice for passing urine and menstrual blood; later, the wound may be opened for intercourse and childbirth; and type $I V$ : any other procedure that injures the female genitalia and is performed without medical justification [2].

In Europe, the demand for reconstruction after FGM/C has increased. This increase was partly due to the empowerment of the female African community [2]. The request for reconstruction arises from a desire that extends beyond a surgical genitalia correction [3]. These women may wish to become "complete" again, because after gaining knowledge about FGM/C, they feel different from other women living in their new society [2]. Although the effects of this surgery on the patient's health depend on the type of FGM/C incurred, all patients experienced a complete or partial removal of the external clitoris and clitoral hood $[1,4]$. Therefore, most surgeries involve correcting clitoral mutilations in these women.

Current guidelines differ among European countries regarding the healthcare of women after FGM/C. For example, clitoris reconstruction is fully reimbursed in France and Sweden, but some countries, such as the UK and the
Netherlands, the issue of whether reconstruction after FGM/C is advisable continues to be debated [5, 6]. Furthermore, more conservative healthcare professionals often consider it inadvisable to support gender identity and female completeness with surgical FGM/C correction, because in their view, this goal can be easily achieved with sex counseling and an education in anatomy [7].

The techniques for reconstructing the clitoris after FGM/C were first described by Pierre Foldès [6]. Other surgeons have reproduced those surgical results [2, 6, 8-14], although the first article about reconstruction was published by Thabet et al. [14]. Nevertheless, to date, the surgical outcomes and emotional consequences that women experience after external genital corrections for FGM/C have not been fully established or recognized in the mainstream scientific medical literature. In the present study, we investigated the outcomes of FGM/C corrective surgery from the patients' viewpoints.

\section{Patients and methods}

\section{Patients}

This is a retrospective study based on a prospectively kept data base of 72 consecutively treated woman (age: $\geq 18$; range 18-53 years) who visited our clinic to request surgery for correcting FGM/C, from January 2010 to December 2020. All patients had immigrated from sub-Sahara Africa 
Fig. 2 Prevalence of FGM types I to IV among the 72 women examined

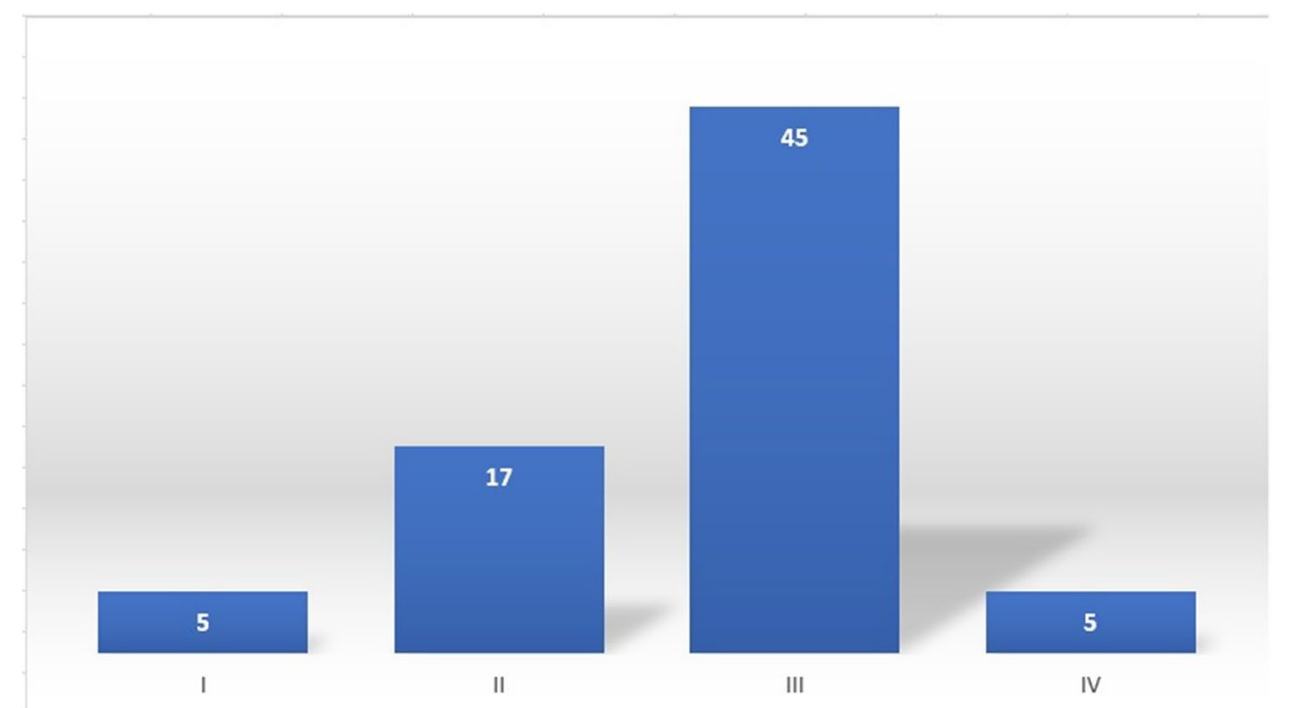

Table 1 Patients' characteristics

\begin{tabular}{lll}
\hline & & Total \\
\hline Total number of patients & & 72 \\
Number of patients operated & & $45(62.5 \%)$ \\
Median age (range) at operation & & 34 years $(18-53)$ \\
Median age (range) at FGM & & 6 years $(1-19)$ \\
Type of FGM (total) & Type I & $5(6.9 \%)$ \\
& Type II & $17(23.6 \%)$ \\
& Type III & $45(62.5 \%)$ \\
& Type IV & $5(6.9 \%)$ \\
\hline
\end{tabular}

or the Middle East and had experienced childhood circumcision [2]. At the beginning of the study, most patients sought treatment on their own, but currently, patients are mostly referred by a general practitioner or gynecologist. Most women had types II and III FGM/C (infibulation) (Fig. 2, Table 1). However, only one patient required de-infibulation of the introitus, because most patients had previously undergone vagina opening for childbirth. The ethical committee of the primary Clinic confirmed that no ethical approval was required for this observational study.

\section{Preoperative workup}

Informed consent was obtained from all patients. Preoperatively, all women were extensively interviewed by a team that comprised a case manager, a female nurse, and a surgeon. Patients also completed a questionnaire during the first consultation to record demographics (i.e., age, country of origin, country of circumcision, age at circumcision). Additionally, patients were asked to select a specific, primary motive for requesting a surgical correction, among five options. Although each patient might have had several motives, we were interested in the one that the patient felt was most relevant:

1- Chronic pain or pain during intercourse.

2- Feelings of rejection and/or shame.

3- Desire to improve feelings about sexuality.

4- Feeling abnormal or incomplete as a woman.

5- Dissatisfaction with a previous treatment performed elsewhere.

After 72 women completed a preliminary work-up, 19 were considered ineligible for primary FGM/C corrective surgery, for the following reasons: (i) the FGM type determined in a physical examination was inconsistent with the extent, severity, or type of mutilation described by the patient $(n=12)$, or (ii) the patient expressed unrealistic expectations $(n=7)$ [2]. We interpreted these situations very carefully, in a multidisciplinary team, which included a gynecologist, plastic surgeon, case manager, and when needed, a sexologist, as described previously [2]. The gynecologist also investigated women with spontaneous vulvar pain, before a decision was made on the procedure $[2,5$, 15]. Another five women were not considered eligible, due to co-morbidities, including posttraumatic stress syndrome, which required management prior to surgery. Furthermore, two women only wanted information about the surgical procedure. Therefore, we enrolled 53 patients in the study. All patients were informed about the possible outcomes, limitations, and possible complications of the surgical procedure, and all provided informed consent.

Of the 53 women eligible for surgery, one eventually decided that she only wanted a Bartholin cyst removed, without an external genital reconstruction of a type IV FGM. Therefore, she was excluded from the study [2]. Another patient was excluded, due to a previous attempt 
Fig. 3 A Pre-operative view of mutilated clitoris. B Postoperative view of reconstructed clitoris. Note how we placed closely-sewn sutures around the clitoral stump to prevent the clitoral stump from retracting. The skin anterior to the clitoris was additionally sutured capturing the underlying connective tissue
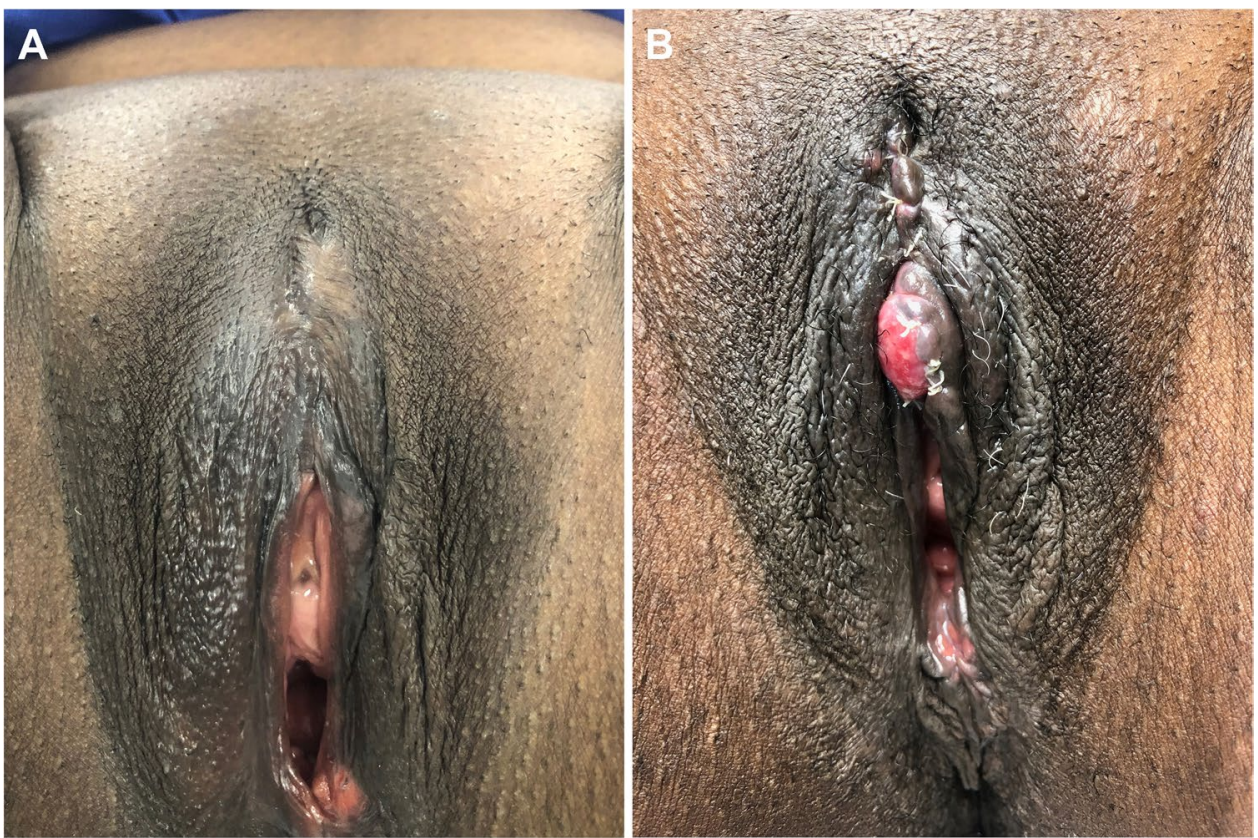

at reconstruction elsewhere, which had inadequate results. Therefore, 51 patients were eligible for an evaluation of the outcome of a primary clitoral construction. However, as of January 2021, 45 patients of these patients were treated, and six patients remain on the waiting list. Thus, the present study included 45 patients.

Among the 45 women that underwent genital reconstruction (mean age: 34.2 years, standard deviation [SD]: \pm 8.44 , range: 18-53 years), one was self-referred from Saudi Arabia, and 44 lived in the Netherlands. Of the 45 women included, $33(73 \%)$ presented with a type III mutilation, with clitoral excision, $9(20 \%)$ had a type II mutilation, 2 (4\%) had a type I mutilation, and one (2\%) had a type IV mutilation.

\section{Treatment}

Patients were administered general anesthesia for the operation to avoid repeating the traumatization. Briefly, patients were placed in the lithotomy position, and upon induction, they received a single intravenous dose of $1500 \mathrm{mg}$ cefuroxime for antibiotic prophylaxis. Two patients required the removal of a pseudo-cyst present in the FGM/C scar prior to clitoral reconstruction. A third patient required treatment for a stenosis in the urethral meatus in addition to clitoral reconstruction.

The Foldès principles were applied in surgery. First, lateral to the symphysis, we identified the dorsal vessels of the clitoral remnant $[2,6,8,9]$. Next, all scar tissues were removed from lateral and ventral sites. Then, we performed a dorsal dissection of the suspensory ligament and folded the clitoral remnant in the ventral direction, towards the vaginal introitus. Then, to prevent the clitoral stump from retracting, we placed closely sewn sutures around the clitoral stump. Next, we sutured the skin anterior to the clitoris with interrupted stitches that captured the underlying connective tissue (Fig. 3) [2].

Three women required an extension of surgery to reconstruct the labia minora. Briefly, skin flaps were raised on both sides of the introitus, and the lateral aspects were covered with a full-thickness skin graft, dissected from the intragluteal fold [2]. A superior approach would have been to reconstruct the vulva or labia minora with an anterior obturator artery perforator flap, as described by Dr. O'Dey. However, that approach required a much longer operating time, and the learning curve was steep [12]. At the end of the reconstruction surgery, a subcutaneous injection of $7.5 \mathrm{mg} / \mathrm{ml}$ ropivacaine hydrochloride was administered to ameliorate postoperative pain.

Postoperatively, all patients received 500/125 g oral amoxicillin/clavulanic acid, three times daily, for 5 days. Women that underwent only clitoris reconstructions were discharged on the day of surgery, with instructions to maintain low activity for three days. Women that required labial reconstructions $(n=3)$ remained in hospital for $24 \mathrm{~h}$ under close observation in case of wound complications. Then, they were discharged and advised to maintain low or minimal activity at home for 5 days.

For the first three postoperative days, all patients received a lidocaine prescription ( $2 \%$ paraffin crème), with instructions to apply a thin layer over the wound, three times daily. They were also prescribed estriol vaginal crème, and instructed to apply a thin layer on and around the wound, once daily, starting on day two, for 3 weeks. These medications were prescribed to prevent pain on voiding or while walking [2]. 
Fig. 4 Reasons for requesting surgery among the 45 women that underwent surgery in the present study

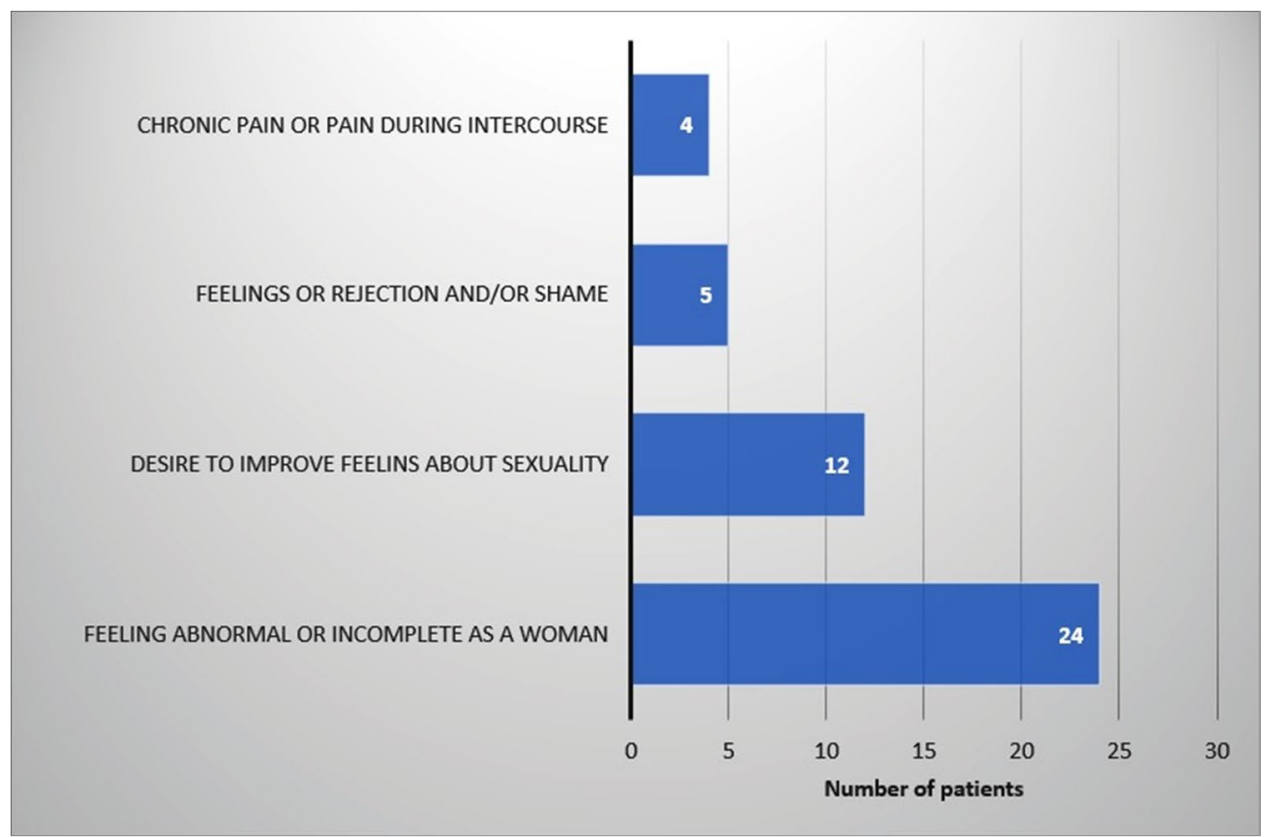

Patients were advised to allow a 3-week recovery period, where they should limit activities, cool the wound, avoid smoking, and avoid heavy physical chores. Moreover, they were advised that full wound healing could require 6 to 12 weeks. Routine follow-ups were conducted in an outpatient clinics at 3 weeks, 3 months, 6 months, and 1 year after surgery. In addition, case managers encouraged all patients to contact them outside of scheduled appointments, whenever necessary.

\section{Patient assessments}

We recorded all postoperative events. All complications were noted, but when re-admission or surgery was required, the event was considered a major complication. Minor complications were treated conservatively.

The case manager monitored patient satisfaction. After surgery, postoperative outcomes were evaluated by use of structured questionnaires. Patients were asked to select between (i) satisfaction or (ii) dissatisfaction with the surgical outcome.

Additionally, the preoperative expectation was compared to the postoperative satisfaction for each patient to determine whether the main reason for surgery was resolved.

\section{Results}

The potential candidates for FGM/C correction unanimously expressed that, by undoing the physical mutilation imposed on them, they could recover personal autonomy. Among the 45 women included in our study, the main reasons for surgery were the lack of feeling complete as a woman and the desire to improve their feelings of sexuality (Fig. 4) [2, $3]$.

We evaluated postoperative outcomes in the 45 patients that had undergone surgery, as of January 2021 . We observed no major complications. Minor complications were noted in 4 patients, including mild local inflammation $(n=3)$ and urinary tract infection $(n=1)$. Two patients experienced postoperative genital pain for a prolonged postoperative period, but recovered completely within 3 months.

The mean follow-up time was 13 months ( \pm 44 weeks; range: $3-184$ months). Six patients (13\%) were lost to follow-up. Thirty-five patients (78\%) reported satisfaction with the outcome and indicated postsurgery improvements in selfesteem (Fig. 5). Four women (9\%) reported disappointments in the aesthetic outcome, but satisfaction with the surgery. Postoperative counseling conducted to clarify patient expectations revealed that the patients expected to gain a more voluminous clitoris. Nevertheless, all women reported that the surgery and additional postoperative education about basic anatomy and the surgical possibilities provided feelings of empowerment and improved their self-esteem.

\section{Discussion}

Infibulation involves excision of the clitoral glans, part of the clitoral body, and the labia minora $[2,16]$. This study showed that corrective surgery for FGM/C was associated with a low complication rate (8.9\%), and more importantly, we only observed minor complications. Our results were consistent with those reported by Foldès and others $[2,6$, 
Fig. 5 Level of satisfaction with surgical result among the 45 women included in the study

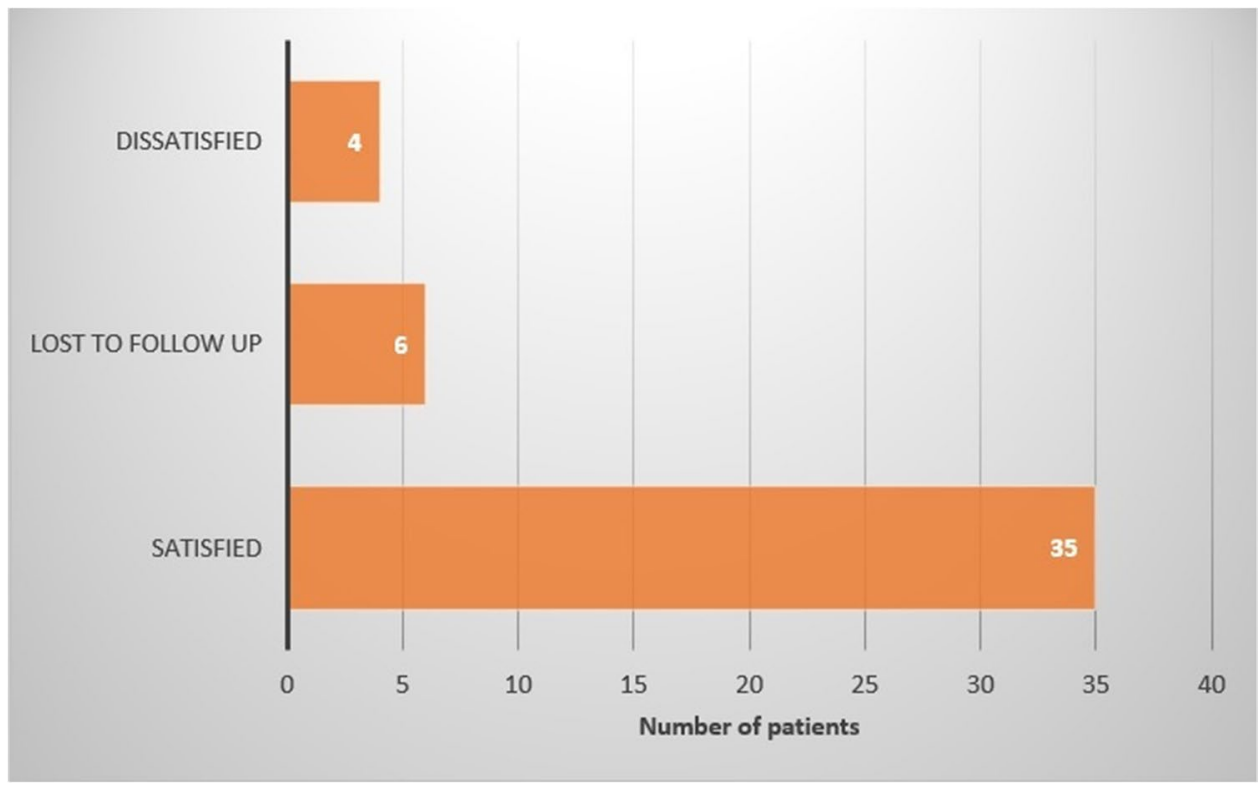

8-14]. Clitoral stump repositioning/reconstruction is always feasible after FGM/C. The surgical procedure is standardized and reproducible, and the complication rates are acceptable [2, 6, 8-14]. According to current literature, among women that undergo FGM/C corrective surgery, up to $80 \%$ report better sexual function within 12 months postoperatively and are likely to experience improvements in self-esteem and self-image $[2,6,8,9,17]$. In the present study, we did not quantify the effects of corrective surgery on quality of life or self-esteem for women with FGM/C. Nevertheless, our results supported the notion that the surgery had positive effects on both quality of life and self-esteem.

We found that, in some cases, the physical examination was inconsistent with the patient's description of their genital mutilation. In our cohort, this discrepancy was prognostic of the outcome of surgery. Indeed, unrealistic expectations about the outcome of surgery may severely hamper recovery from treatment.

More conservative healthcare professionals often reject FGM/C-corrective surgery, because they claim that a woman's gender identity and sense of female completeness can be supported without surgery, by offering sex counseling and an education in female anatomy [7]. In our opinion, this is a simplified, binary viewpoint that fails to honor the patient's autonomy and bodily integrity. Furthermore, that opinion may be based on biases held by some professionals that stem from a lack of understanding of the complexity of women's sexuality in the socio-cultural context of settings that permit FGM/C practices [3, 7]. Sexuality involves the mind, the body, human interactions, and self-esteem. Despite our difficulty in understanding the motivation for FGM/C, this practice does not necessarily affect psychosexual life in a negative manner, even though it can impact sexuality
[16]. In the Netherlands, a relatively small number of women have sought a surgical solution to this type of mutilation. As healthcare professionals, we should foster an open-minded, culturally sensitive approach to patients with FGM/C. A thorough assessment of the need for surgery is essential for appropriate patient selection. However, we cannot and must not hide behind the assumption that there is no evidence that this treatment has a scientific basis. A treatment that has not been proven effective is not the same as a treatment that has been proven ineffective. Moreover, it is often difficult to perform a systematic review on studies with small numbers of patients, without rejecting many articles, and thereby, influencing the outcome [18].

It has been internationally recognized that FGM/C is a violation of human rights. In Europe, all forms of FGM/C have been officially banned [19]. Given that FGM/C is considered a mutilation we must take the next step of enforcing a fundamental human right by endeavoring to reverse the mutilations incurred in women with FGM/C whenever a correction is requested. Accordingly in our opinion genital reconstruction surgery should be included in the care offered to women with FMG/C [2]. Although not every circumcised woman will choose surgery, nevertheless, when corrective surgery is requested, it is important to carefully select appropriate patients to ensure optimal quality of care and avoid disappointments in the outcome.

\section{Conclusions}

Clitoral reconstruction techniques have been well-established for women that request corrective surgery for FGM/C. In the last 10 years, there has been an increase in 
the awareness that clitoral reconstruction is possible in the Netherlands and throughout Europe. Our 10-year experience and results supported the positive trends reported previously.

Based on our results, we concluded that clitoral reconstructive surgery led to positive, predictable results, with few minor surgical complications, after specifically selecting appropriate patients. Patients with FGM/C that sought a surgical solution reported postoperatively that their self-esteem and body image had improved. In our opinion, clitoral reconstructive surgery is a minor surgery that should be offered to women that specifically request it, and it should be covered by health insurance.

\section{Declarations}

Ethics approval The ethical committee of the primary Clinic has confirmed that no ethical approval is required for this retrospective study.

Consent to participate and consent to publish The authors affirm that all patients provided informed consent to participate in this study and to publish their data. This included the informed consent to publish the images in Fig. 3.

Conflict of interest R.B. Karim, D.E.N.B. Karim, J.J.M.L. Dekker, and M.J. Middelburg declare no conflict of interest.

Open Access This article is licensed under a Creative Commons Attribution 4.0 International License, which permits use, sharing, adaptation, distribution and reproduction in any medium or format, as long as you give appropriate credit to the original author(s) and the source, provide a link to the Creative Commons licence, and indicate if changes were made. The images or other third party material in this article are included in the article's Creative Commons licence, unless indicated otherwise in a credit line to the material. If material is not included in the article's Creative Commons licence and your intended use is not permitted by statutory regulation or exceeds the permitted use, you will need to obtain permission directly from the copyright holder. To view a copy of this licence, visit http://creativecommons.org/licenses/by/4.0/.

\section{References}

1. World Health Organization (2008) Eliminating female genital mutilation: an interagency statement - OHCHR, UNAIDS, UNDP, UNECA, UNESCO, UNFPA, UNHCR, UNICEF, UNIFEM, WHO. World Health Organization. https://apps.who.int/iris/handle/10665/43839. (Accessed 1 Dec 2021)

2. Karim RB, Dekker JJML (2017) Outcome of external genital reconstruction after female genital mutilation (FGM): a pilot in selected patients in the Netherlands. Clin Surg 2:1483
3. Jordal M, Griffin G, Sigurjonsson H (2019) "I want what every other woman has": reasons for wanting clitoral reconstructive surgery after female genital cutting - a qualitative study from Sweden. Cult Health Sex 21(6):701-716

4. WHO (2016) WHO guidelines on the management of health complications from female genitale mutilation: World Health Organization. http://www.who.int/reproductivehealth/topics/fgm/management-healthcomplications-fgm/en/. (Accessed 1 Dec 2021)

5. Caillet M, O Neill S, Minsart A, Richard F. Addressing FGM with Multidisciplinary Care. The Experience of the Belgian Reference Center CeMAViE. Current Sexual Health Reports. 2018;10:44-9.

6. Foldès P, Cuzin B, Andro A (2012) Reconstructive surgery after female genital mutilation: a prospective cohort study. Lancet. 380(9837):134-41.

7. Catania L, Abdulcadir O, Puppo V, Verde JB, Abdulcadir J, Abdulcadir D (2007) Pleasure and orgasm in women with Female Genital Mutilation/Cutting (FGM/C). J Sex Med. 4(6):1666-78.

8. Foldes P, Louis-Sylvestre C (2006) Results of surgical clitoral repair after ritual excision: 453 cases. Gynecol Obstet Fertil 34(12):1137-1141

9. Foldes P (2004) Reconstructive plastic surgery of the clitoris after sexual mutilation. Prog Urol 14(1):47-50

10. Ouédraogo CM, Madzou S, Touré B, Ouédraogo A, Ouédraogo S, Lankoandé J. (2013) Practice of reconstructive plastic surgery of the clitoris after genital mutilation in Burkina Faso. Report of 94 cases. Ann Chir Plast Esthet 58(3):208-15

11. Madzou S, Ouédraogo CM, Gillard P, Lefebvre-Lacoeuille C, Catala L, Sentilhes L et al (2011) Reconstructive surgery of the clitoris after sexual mutilation. Ann Chir Plast Esthet 56(1):59-64

12. O'Dey DM (2017) Complex vulvar reconstruction following female genital mutilation/cutting. Urologe A 56(10):1298-1301

13. Mañero I, Labanca T (2018) Clitoral reconstruction using a vaginal graft after female genital mutilation. Obstet Gynecol 131(4):701-706

14. Thabet SM, Thabet AS (2003) Defective sexuality and female circumcision: the cause and the possible management. J Obstet Gynaecol Res 29(1):12-19

15. Sigurjonsson H, Jordal M (2018) Addressing female genital mutilation/cutting (FGM/C) in the era of clitoral reconstruction: plastic surgery. Curr Sex Health Rep 10(2):50-56

16. (2012) Seven things to know about female genital surgeries in Africa. Hastings Cent Rep 42(6):19-27

17. Seifeldin A (2016) Genital reconstructive surgery after female genital mutilation. Obstet Gynecol Int J 4(6):00129

18. Leye E (2008) Female genital mutilation: a study of health services and legislation in some countries of the European Union. Ghent University, Faculty of Arts and Philosophy, Ghent, Belgium, ICRH Monografieën

19. Abdulcadir J, Rodriguez MI, Say L (2015) A systematic review of the evidence on clitoral reconstruction after female genital mutilation/cutting. Int J Gynaecol Obstet 129(2):93-97

Publisher's note Springer Nature remains neutral with regard to jurisdictional claims in published maps and institutional affiliations. 